\title{
Sciatic Nerve
}

National Cancer Institute

\section{Source}

National Cancer Institute. Sciatic Nerve. NCI Thesaurus. Code C52810.

The longest single nerve that is formed by the merging of the ventral rami of the $L 4, L 5$, and $\mathrm{S} 1$ in the pelvis and passes down the lower limb where it divides into the common peroneal and tibial nerves. 